\title{
Assessment of Forest Road Network Alternatives for Pine Resin Extraction
}

\author{
Ahmad Budiaman*, Heryana \\ Department of Forest Management, Faculty of Forestry, Bogor Agricultural University, \\ Academic Ring Road, Campus IPB Dramaga, PO Box 168, Bogor 16680, Indonesia
}

Received April 17, 2012/Accepted February 12, 2013

\begin{abstract}
Pine resin, one type of non-timber forest products (NTFPs), is important for Indonesia. In addition to its high economic value, pine resin also has bright domestic and international market prospects. Utilization of commercial pine resin has been carried out in Indonesia, but the forest road network required for extracting pine resin has not been specifically planned. To date, the planning and selection of forest road network in forest management in Indonesia are intended only for the extraction of timber products and have not been integrated with the use of NTFPs; also, they have not considered the economic, ecological, and social aspects a whole. Planning and selection of forest road network have focused more on economic aspects only. This study aimed at planning and assessing the forest road network for extracting pine resin by considering the economic, ecological, and social criteria. Decisionmaking method used to select the best forest road network was utility analysis. Indicator used included road length, road density, a correction factor for manual carrying of pine resin, pine resin carrying distance, road construction cost, and productivity of carrying and extracting pine resin. The result of the utility analysis indicates that an alternative of forest road network for extracting pine resin has no the whole best indicators, but it has the highest utility value. This study suggested that the use of the utility analysis help the decision makers to selects process for forest road network alternative easily and rapidly.
\end{abstract}

Keywords: pine resin, forest road network, utility analysis, non-timber forest products (NTFPs)

*Correspondenceauthor, email: abudiam@yahoo.co.id,telp.+62-251-8421385

\section{Introduction}

Non-Timber Forest Products (NTFPs) are biological materials other than timber produced from forests (Chamberlain et al. 2002; Kilchling et al. 2009). NTFPs play an important role in sustainable forest management. In the previous decades, NTFPs were considered as byproducts; however, there has been a change of paradigm from timberbased forest management to multi-function or multi-benefitbased forest management (Garcia-Fernandez et al. 2008; Kilchling et al. 2009; Chiou et al. 2010), and timber-based forest management has been integrated with the NTFPs as practiced in Bolivia (Guariguata et al. 2008). In addition, NTFPs can be a source of income for rural communities, and the income has continued to increase in the tropical areas, and some forest communities can meet their needs from NTFPs (Lacuna-Richman 2003), and even NTFPs can have an interest as a source of additional income for the forestry sector and has great demand potential as occurred in Switzerland (Kilchling et al.2009).

Pine resin is an important NTFP for Indonesia, and has a high economic value and good market prospect. Indonesia has an important position in the pine resin world trade. At present, Indonesia is the second largest producer of pine resin in the world after China. The pine resin production of China reached approximately $60 \%$ of the total world production of pine resin, while the production of pine resin in Indonesia only reached $10 \%$ (FAO 2011). Utilization of pine resin in Indonesia has been conducted since the development of pine plantations in Java Island, and it is currently expanding to several islands outside Java, such as Sumatra, Kalimantan and Sulawesi. Most of the Indonesia's pine resin is produced from plantation forests of Java Island, and only a small proportion is produced irregularly from outside Java, especially from Sumatra (Irawan et al. 2007; FAO 2011).

Pine forests in Indonesia grow in different forest types such as industrial plantation forests, natural pine forests and protected forests, most of which are in hilly regions, and mountainous areas. Because of the locations of pine forests, extraction of pine resin should give more attention to ecological aspects, in addition to the economic, technical, and social ones. The carrying and extraction of pine resin require good planning and selection process of forest road network because forest road network planning will facilitate the storage and extraction of pine resin (Acar et al. 2003). Planning and construction of classical forest road network always consider four criteria: technical capability, economic efficiency, environment, and social integrity (Heinimann 1998), so that the sustainable utilization of NTFPs can be realized. 
Most road systems built in forests provide accesses for resource extraction and extraction purposes (Janowsky \& Becker 2003), so that the forest road planning standards will be different for each forest type as in production forests, national parks and protected areas (Demir 2007). In forest management in Indonesia, planning and evaluation of the forest road network still focus on providing access for extraction of forest products such as timber both from plantation and natural forests. Although the interest of pine resin has a tendency to increase, the supply of forest road network to extract pine resin has not been specifically conducted. This is due to the fact that the construction of forest road network is the most expensive forestry activity (Demir 2007; Najafi et al. 2008; Abdi et al. 2009), while the economic value of pine resin extraction is less than that of timber extraction.

The studies on planning and assessment of forest road network for extraction and transportation of pine resin have not been much conducted in Indonesia. On the other hand, to maintain a balance between the utilization of pine resin and conservation of mountainous pine forests, the method of decision-making in selecting forest road network requires to be evaluated beforehand and does not only consider one aspect. This study aimed at assessing the planning and selection of the best alternative for forest road network for the extraction of pine resin by using the multi-criteria decision making technique.

\section{Methods}

Description of the study site This study was conducted at Gunung Walat Educational Forest (GWEF), located approximately $106 \mathrm{~km}$ from Jakarta to the southeast and $2.4 \mathrm{~km}$ from the axis of the road from Sukabumi to Bogor. Geographically, GWEF is located between $106^{\circ} 48^{\prime} 27^{\prime \prime}$ and $106^{\circ} 50^{\prime} 29^{\prime \prime}$ of the eastern longitudes and between $6^{\circ} 54^{\prime} 23^{\prime \prime}$ and $6^{\circ} 55^{\prime} 35^{\prime \prime}$ of the south latitudes. Administratively, it is located in Cibadak District, Sukabumi Regency West Java. It is managed by an independent management unit under the supervision of the Faculty of Forestry, Bogor Agricultural University. The total area of GWEF reaches 359 ha. Almost all GWEF forests are planted with several commercial species such as Agathis lorantifolia, Pinus merkusii, Schima wallichii, Maesopsis eminii, Swietenia macrophylla, Altingia excelsa, Dalbergia latifolia, Gliricidae sp., Paraserianthes falcataria, Shorea sp., and Acacia mangium. The main objectives of the GWEF management include forest conservation, education and service to the community; however, it also produces commercial NTFPs such as pine resin and copal. Felling trees is not permitted in the forests, except for preservation cutting due to natural disasters and forest fires. GWEF lies at an altitude of 460-715 $\mathrm{m}$ above sea level. The topography varies from gently undulating to hilly in the southern part, and steep terrain in the northern part. Soil types of GWEF include quite sensitive soil (latosol), sensitive soil (podzolic) and highly sensitive soil (litosol). A transition area with karst rock types is found in the southwest. According to Schmidt and Ferguson's climate classification, the climate in the region of GWEF includes type $\mathrm{B}$ with a value of $\mathrm{Q}=14.3$ to $33 \%$. The amount of annual rainfall ranges from 1600-4400 mm; furthermore, the maximum temperature during the day is $29{ }^{\circ} \mathrm{C}$ and minimum temperature at night is $19^{\circ} \mathrm{C}$.

Data collection The study was conducted for 2 months in 2011. Data were collected through direct measurement of key variables of forest road network such as the length and width of main roads, secondary roads, and paths for carrying pine resin, shortest mean carrying distance of pine resin (SMCD), actual mean carrying distance of pine resin (AMCD), pine resin tapping productivity, pine resin extraction time, pine resin extraction distance, and number of pine resin extraction trips. This study also collected secondary data such as road construction cost and resin production in 2011. Pine resin tapping was conducted on Pinus merkusii trees with a diameter ranging from 35 to 65 $\mathrm{cm}$. Pine stands spread evenly in the eastern and northern parts of GWEF. The pine resin was then carried to the temporary pine resin collection area located on the side of the road. As many as 10 people aged from 21 to 26 years old as the samples were involved in the pine resin tapping. The pine resin from the pine resin collection area was transported by a pick-up vehicle to the end pine resin collection area located at the base camp. The pine resin samples were carried manually as many as 20 times, and the number of samples for the pine resin extraction was 7 trips.

This study assessed 4 types of forest road networks, i.e. one forest road network that already exists in the field and three other forest road networks which will be mapped on the forest road network map of GWEF (Figure 1). Considerations taken in designing the three forest road networks included the location of pine resin collection area, landscape structure; distribution of pine stands, soil type, topography, and protected areas. The 4 forest road networks for pine resin extraction are described as follows:

1 The forest road network with a status quo (SQ) consists of a main road, secondary road, and path for carrying the pine resin manually. The SQ main road extends from the south to the north of the GWEF. The forest road network has two secondary roads located in the northern part of the GWEF region, and the secondary roads extend from the east to the west of the GWEF. There are 13 sections of path used for carrying pine resin, and they are randomly scattered in the region of GWEF. In this alternative, there are two temporary collection areas of pine resin, i.e. one in the west and the other one in the base camp.

2 Alternative 1 (A-1). The patterns of the main and secondary roads are similar to those of the SQ forest road network; however, the paths used for carrying pine resin manually were redesigned. Two sections of path for carrying pine resin were removed from the SQ network; as a result, there are only 9 carrying path sections left. In this alternative, 2 temporary collection areas of pine resin were added in the eastern part of the GWEF region which has relatively more pine stands. The purpose of the addition of these 2 extra pine resin collection areas is to provide easier access to the largest producing region of pine resin.

3 Alternative 2 (A-2). Alternative 2 was developed from 
A-1 forest road network in which one section of the secondary roads was removed from the A-1 network, and a new secondary road will be constructed to connect the base camp with the nearest pine resin collection area located in the eastern part of the GWEF region. In addition, the 3 path sections for carrying the pine resin were removed from the A-1 network; therefore, there will be 6 path sections for carrying the resin pine in this network. Also another 3 temporary pine resin collection areas can be found in this alternative.

4 Alternative 3 (A-3). Alternative 3 was developed from A-2 forest road network in which the location of the main road and secondary road was changed from their original location. The main road at the A-3 forest road network was designed to connect between the eastern and western parts of GWEF region, while the secondary road connects the southern and northern parts of GWEF region. In addition, one path section for carrying pine resin and one pine resin collection area were removed from the A-2

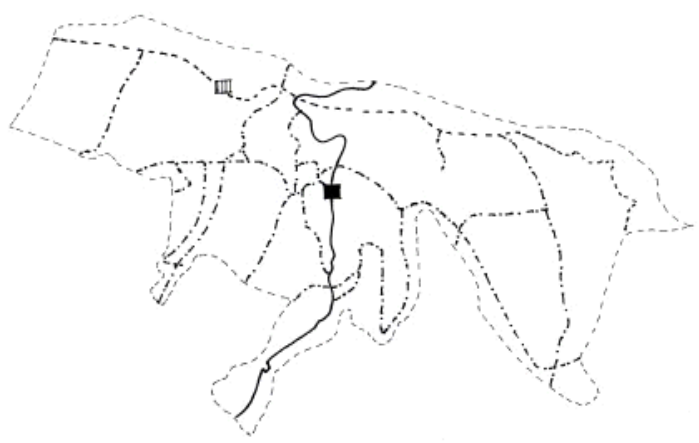

Status Quo (SQ)

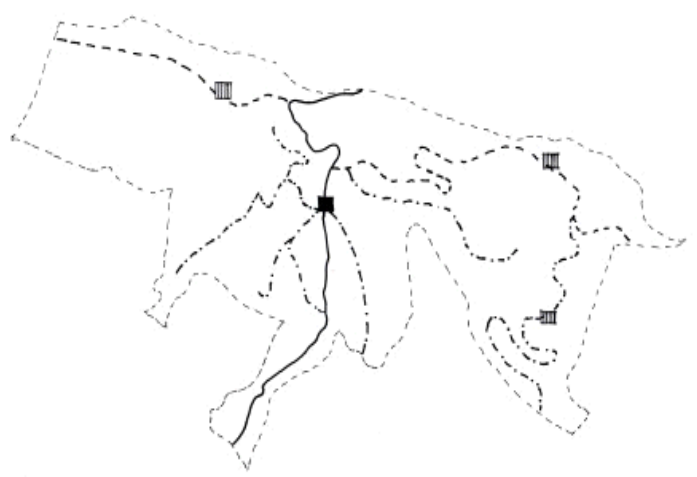

Alternative 2 (A-2) network; as a result, there are only 5 path sections for carrying pine resin and 2 temporary pine resin collection areas.

The parameters used to assess the quality of the forest road network for extracting pine resin included road density, road spacing, SMCD, AMCD, and correction factor for pine resin carrying distance (CF). SMCD was obtained by measuring the shortest distance from the area of pine resin tapping to the temporary pine resin collection area. The SMCD is identical with the shortest mean skidding distance for the extraction of timber (REm) (Dietz et al. 1984). SMCD measurement was carried out by making a grid with the size of $1 \times 1 \mathrm{~cm}$ on a forest road network map with a $1: 20,000$ scale. AMCD was obtained by measuring the actual distance of carrying pine resin. The AMCD is identical to the actual mean skidding distance in the field during the extraction of timber (REt) (Dietz et al. 1984). The equation used to calculate the CF was the AMCD/SMCD. Road density was expressed in road length ha ${ }^{-1}$, and road

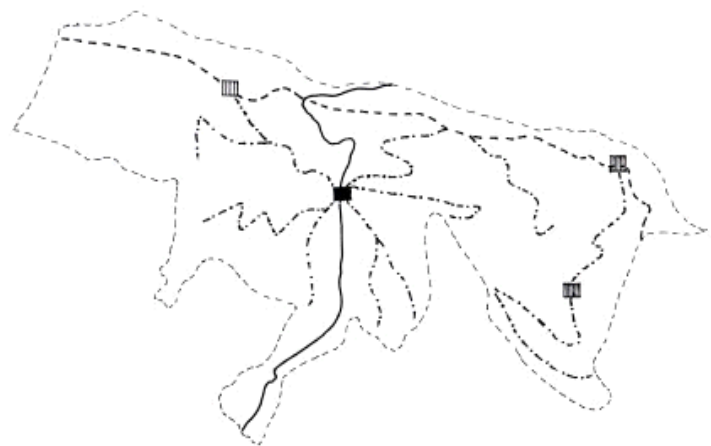

Alternative 1 (A-1)

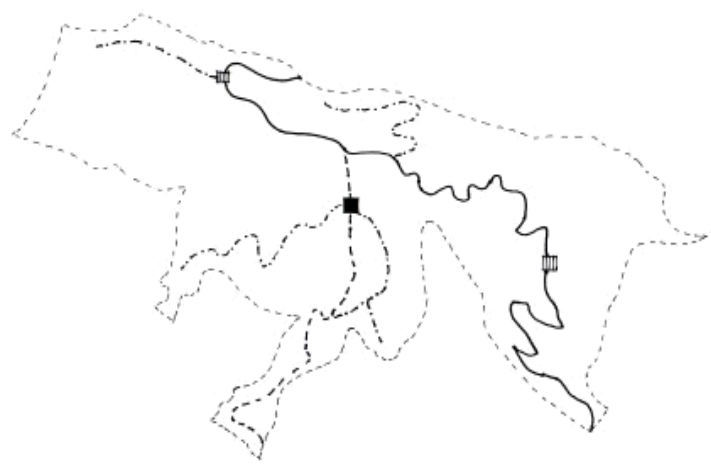

Alternative 3 (A-3)

Figure1 The four alternatives of forest road networks for pine resin extraction. Mainroad ( $\boldsymbol{\square})$, secondary road ( $\boldsymbol{\square} \boldsymbol{\mathbf { m }})$, carrying

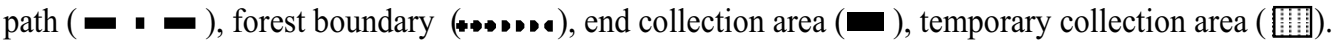


spacing was expressed in the distance between roads used for transporting pine resin (m) (Dietz et al. 1984; Elias 2008).

The analysis method used to select the best alternative of forest road network for pine resin extraction was Utility Analysis. This analysis is one of the decision-making tools that considers multi-criteria and multi-objectives. The utility analysis used in this study consisted of 5 steps, namely, the development of goal system, criteria setting, alternative development, determination of the criterion fulfillment level, the calculation of utility value, and the ranking of the selected alternatives based on the highest utility value (Zangemeister 1973). The goal to be achieved at the highest hierarchy was to obtain the best alternative forest road network for the pine resin extraction. There were 3 criteria used in this analysis, namely, economic, ecological, and social criteria. Indicators set for the economic criteria included the construction cost of the main roads and secondary roads, CF and distance for carrying pine resin from the tapping area to the pine resin collection area. Indicators set for ecological criteria included the length and density of the main roads, secondary roads, and paths for carrying pine resin, and opened area due to the existing roads. Meanwhile, indicators set for social criteria included the productivities of pine resin tapping and extraction. Indicators set for the forest road network selection and direction of preferences are presented at Table 1 .

The total of the utility value of each alternative for forest road network was obtained by adding utility values of all indicators that had been transformed from nominal values to interval scale values. The scale value used is $1-10(1=$ very poor, $10=$ excellent). If the preference direction of indicator is a minimum, the lowest indicator value will get the highest value and the highest indicator value will have the lowest scale value. On the other hand, if the preference direction of indicator is a maximum, the highest value of the indicator will have the highest scale value, and the lowest indicator value has the lowest scale value.

\section{Results and Discussion}

Forest road network quality The quality of forest road network for extracting pine resin can be determined by key parameters such as the road density, road spacing, SMCD, $\mathrm{AMCD}$, and $\mathrm{CF}$. The forest road system analyzed consists of main roads, secondary roads, and paths for carrying pine resin. The average width of main roads, secondary roads, and paths used for carrying pine resin is $5.3 ; 4.4$ and $1.98 \mathrm{~m}$ respectively. The width of the main and secondary roads was established in accordance with the purposes of pine resin extraction and types of transport vehicles that will pass these roads. The main and secondary roads were designed for small transporting vehicles (pick-up or the like).

SQ forest road network has the same road density and road spacing of the main and secondary roads as A-1, and A2 , while A-3 has the greatest main road density and smallest secondary road spacing of the four alternatives. The SQ forest road network, A-1 and A-2 have greater AMCD than A-3 but smaller secondary road density than A-3. The SQ road network, A-1, and A-2 have the same secondary road spacing i.e. $552.5 \mathrm{~m}$, and their AMCD ranges from 887.2 to $988.5 \mathrm{~m}$. The road network of A-3 has a secondary road spacing of $1,087 \mathrm{~m}$ and AMCD of $716.2 \mathrm{~m}$. In the ideal model (flat area), if short-distance transport (skidding or carrying) is carried out in one direction, the distance of its skidding is $1 / 2$ of the road spacing (Dietz et al. 1984). The mean carrying distance will increase in accordance with the increase of slope terrain. If the slope terrain becomes heavier, the mean carrying distance will be greater than its road spacing. The AMCD values of the four forest road networks are greater than $1 / 2$ of their road spacing. This indicates that GWEF region has a heavy terrain (a mountainous region). Lotfalian et al. (2011) reports that it has an average slope of $40 \%$ and forest road network with a road spacing of $500 \mathrm{~m}$, and its actual skidding distance in the field was $525.9 \mathrm{~m}$.

Table 1 Criteria, indicators and preference direction of indicators used to select the best alternative for the forest road network for the transport of pine resin

\begin{tabular}{|c|c|c|c|}
\hline Criteria & Indicators & Unit & Preference direction \\
\hline \multirow[t]{8}{*}{ Ecology } & Length of main road & $(\mathrm{km})$ & Minimum \\
\hline & Length of secondary road & $(\mathrm{km})$ & Minimum \\
\hline & Length of carrying path & $(\mathrm{km})$ & Minimum \\
\hline & Density of main road & $\left(\mathrm{m} \mathrm{ha}^{-1}\right)$ & Minimum \\
\hline & Density of secondary road & $\left(\mathrm{m} \mathrm{ha}^{-1}\right)$ & Minimum \\
\hline & Density of carrying path & $\left(\mathrm{m} \mathrm{ha}^{-1}\right)$ & Minimum \\
\hline & Opened area due to the main road & (ha) & Minimum \\
\hline & Opened area due to the secondary road & (ha) & Minimum \\
\hline \multirow[t]{3}{*}{ Economy } & Correction factor (CF) & - & Minimum \\
\hline & Distance of carrying the pine resin & (m) & Minimum \\
\hline & Cost of road construction & (Rp) & Minimum \\
\hline \multirow[t]{2}{*}{ Social } & Productivity of carrying pine resin & $\left(\mathrm{kg} \mathrm{km}^{-1}\right.$ hour $\left.^{-1}\right)$ & Maximum \\
\hline & Productivity of pine resin extraction & $\left(\mathrm{kg} \mathrm{km}^{-1}\right.$ hour $\left.^{1}\right)$ & Maximum \\
\hline
\end{tabular}


Table 2 Quality of the 4 alternatives for forest road network for pine resin extraction

\begin{tabular}{lccccccccc}
\hline Alternative & \multicolumn{2}{c}{ Road density $\left(\mathrm{m} \mathrm{ha}^{-1}\right)$} & \multicolumn{3}{c}{ Road spacing $(\mathrm{m})$} & \multicolumn{3}{c}{$\begin{array}{l}\text { Mean } \\
\text { distance }(\mathrm{m})\end{array}$} \\
& \multicolumn{3}{c}{} & & \multicolumn{3}{c}{ Carrying } & CF \\
& Main & Secondary & Path & Main & Secondary & Path & SMCD & AMCD & \\
\hline SQ & 13.7 & 18.1 & 70.5 & 729.9 & 552.5 & 141.8 & 528.1 & 988.5 & 1.87 \\
A-1 & 13.7 & 18.1 & 47.6 & 729.9 & 552.5 & 210.1 & 530.7 & 974.4 & 1.84 \\
A-2 & 13.7 & 18.2 & 30.5 & 729.9 & 552.5 & 327.9 & 532.0 & 887.2 & 1.67 \\
A-3 & 21.6 & 9.2 & 16.9 & 463.0 & 1087.0 & 591.7 & 561.7 & 716.2 & 1.28 \\
\hline
\end{tabular}

Table 3 Quantification of indicators of the 4 alternatives for forest road networks for pine resin extraction

\begin{tabular}{|c|c|c|c|c|c|}
\hline \multirow[t]{2}{*}{ Criteria } & \multirow[t]{2}{*}{ Indicators } & \multicolumn{4}{|c|}{ Alternatives for forest road network } \\
\hline & & SQ & A-1 & A-2 & A-3 \\
\hline \multirow[t]{8}{*}{ Ecology } & Length of main road & 2.92 & 2.92 & 2.92 & 4.59 \\
\hline & Length of secondary road & 3.85 & 3.85 & 3.88 & 1.96 \\
\hline & Length of carrying path & 15.02 & 10.14 & 6.48 & 3.60 \\
\hline & Density of main road & 13.7 & 13.7 & 13.7 & 21.6 \\
\hline & Density of secondary road & 18.1 & 18.1 & 18.1 & 9.2 \\
\hline & Density of carrying path & 70.5 & 47.6 & 30.5 & 16.9 \\
\hline & Opened area due to the main road & 1.55 & 1.55 & 1.55 & 2.43 \\
\hline & Opened area due to the secondary road & 1.69 & 1.69 & 1.71 & 0.86 \\
\hline \multirow[t]{3}{*}{ Economy } & Corection factor (CF) & 1.87 & 1.84 & 1.67 & 1.28 \\
\hline & Distance of carrying pine resin & $2,455.3$ & $1,955.5$ & $1,927.0$ & $1,742.3$ \\
\hline & $\begin{array}{l}\text { Cost of road construction ( } \mathrm{Rp} \\
1,000)\end{array}$ & 0 & 315,400 & 991,697 & $1,682,150$ \\
\hline \multirow[t]{2}{*}{ Social } & Productivity of carrying pine resin & 84.34 & 95.49 & 77.03 & 137.55 \\
\hline & Productivity of pine resin extraction & 195.03 & 239.89 & 219.08 & 275.42 \\
\hline
\end{tabular}

Roads used for carrying pine resin in GWEF were constructed as paths with an average width of $1.98 \mathrm{~m}$. From the four alternatives for forest road networks for the pine resin extraction in the study area, it can be seen that the forest road network with a small road spacing has a high $\mathrm{CF}$, and a large road spacing has a low CF. Kanzaki et al. (1990) states that a correction factor of the transport system will be close to 1 , if the density of the road is increasing. On a road system with a narrow width of path in a heavy terrain (a mountainous region), it is found that the pattern of forest road network with a road spacing of $222.94 \mathrm{~m}$ has a correction factor of 1.215 . This means that low road spacing has a low $\mathrm{CF}$. The planning and assessment of forest road networks for pine resin extraction in GWEF obtained the opposite results. This shows that the AMCD in GWEF is much greater than their SMCD. One of the reasons is that most of the tappers take pine resin directly to the end collection area which is much further than the temporary pine resin collection area. Based on the indicators of $\mathrm{CF}, \mathrm{A}-3$ has the smallest correction factor for carrying the pine resin (1.28), although their road spacing reaches $591.7 \mathrm{~m}$. The quality and intensity of the four alternatives for forest road networks for pine resin extraction are presented at Table 2 .

Most of the main and secondary roads on all alternatives for forest road network have a longitudinal slope extending up to $10 \%$. A-3 has the highest longitudinal slope of $16.6 \%$, the SQ of $18.9 \%$, A-2 of $15.4 \%$, and A-1 of $15.7 \%$. The paths used for carrying the pine resin have a longitudinal slope extending approximately more than $15 \%$. The largest longitudinal slope of the paths used for carrying pine resin on the SQ, A-1, A-2, and A-3 reach 20.2, 17.0, 15.8, and 19.7\% respectively. Elias (2008) adds that the longitudinal slope of forest road extending up to $20 \%$ for one road section whose maximum length reaches $500 \mathrm{~m}$ is still allowed, if it does not cause a major impact on the construction process. Thus, technically, the main and secondary roads planned by GWEF for pine resin extraction are still within the allowable standards.

The best forest road network for transport of pine resin The indicator values for each criterion for each alternative for forest road networks for pine resin extraction are presented in Table 3. Based on the criteria of the length of main and secondary roads, the forest road networks that have the shortest length of main road $(2.92 \mathrm{~km})$ include SQ, A-1, and A-3 forest road networks, while A-3 has the longest length of main road $(4.96 \mathrm{~km})$. Of the four alternatives, A-3 has the greatest main road density but has the smallest secondary road density (Table 2). A-3 has the largest width of opened area due to the main road, and SQ, A-1, and A-2 forest road networks have the smallest width. As for the secondary road, the largest width of opened area is found in the forest road networks of SQ, A-1, and A-2 and the lowest is in A-3. Based on the indicators of main road density and 
opened area width due to road construction, the forest road networks of SQ and A-1 become the best alternative for pine resin extraction. The reason for grouping the indicators of road length and road density into the ecological criteria is that the main objective to be achieved in ecological criteria is to minimize the environmental damage caused by road construction, and this ecological objective will be achieved when road construction is minimized. The larger the road density is, the greater the width of opened area for road construction; as a result, the potential for environmental damage will be even greater. Therefore, the utilization of renewable resources and environmental services becomes the primary focus at present, so road construction is conducted as minimally as possible (Chiou et al. 2010), and every aspect of road construction of different types will have different negative consequences on the environment (Liu et al. 2008), such as the structure of ecosystem, dynamics of ecosystem functions, and direct impacts on the components of the ecosystem, including species composition (Coffin 2007). Freitas et al. (2010) adds that road density has the strongest relationship with forest deforestation and fragmentation, especially if the forest roads become parts of the permanent landscape.

The length of paths in A-3 reaches 3,694.5 m. Of the 4 alternatives, A-3 has the shortest path length. The length of the paths of A-3 is 5 times shorter than that in SQ network. Besides having the shortest path length, A-3 has more paths spread evenly in the location of pine resin tapping, thus providing the best accessibility. A-3 has the shortest AMCD $(716.2 \mathrm{~m})$, while the value of the longest AMCD is obtained from the SQ forest road network $(988.5 \mathrm{~m})$. A-3 has the smallest AMCD, and this is because the main road divides into two regions of pine resin tapping so that the location of the temporary pine resin collection area is relatively closer to areas of pine resin tapping. The road system designed for A3 does not require a large number of paths used for the transport of pine resin. The CF values of 4 alternative forest road networks range from 1.28 to 1.87 . The SQ forest road network has the greatest $\mathrm{CF}$, while $\mathrm{A}-3$ has the smallest $\mathrm{CF}$. The correction factor value indicates the correction of the AMCD based on the SMCD. The ideal CF value is 1 , indicating that the AMCD is equal to the SMCD. A-3 is the best alternative forest road network, since the value of $\mathrm{CF}$ approaches 1 . Based on the criteria of the value of $\mathrm{CF}, \mathrm{A}-3$ is the best alternative for forest road network for pine resin extraction.

The total cost of road construction in alternative 1 is Rp315,358, while the cost of A-2 and A-3 are Rp991,697,017 and Rp1,682,150,384, respectively. A-1 cost is the least, because in A-1 there will be no construction of main and secondary roads. A-3 forest road network requires the highest cost in constructing the main and secondary roads because their length reaches $4,600 \mathrm{~m}$ and $1,959.7 \mathrm{~m}$ respectively. Based on the indicators of road construction cost, the SQ forest road network is the best alternative for pine resin extraction.

The average productivity for pine resin extraction is $479.78 \mathrm{~kg}$ hour ${ }^{-1}$, while the productivity of carrying pine resin is $115.54 \mathrm{~kg}$ hour $^{-1}$. Based on the indicators of productivities for carrying and extracting pine resin, A-3 has the highest productivity for carrying and extracting pine resin i.e. $137.55 \mathrm{~kg} \mathrm{~km}^{-1}$ hour ${ }^{-1}$ and $275.42 \mathrm{~kg} \mathrm{~km}^{-1}$ hour ${ }^{-1}$ respectively. Based on these indicators, A-3 is the best for forest road network for pine resin extraction.

Based on the nominal value of each indicator, it can be seen that every forest road network has some advantages and disadvantages; therefore, the best alternative selection is strongly influenced by the objectives of the forest

Table 4 Utility value and ranking of the four alternatives for forest road network for pine resin extraction

\begin{tabular}{|c|c|c|c|c|c|}
\hline & \multirow[t]{2}{*}{ Indicators } & \multicolumn{4}{|c|}{ Alternatives for forest road network } \\
\hline & & SQ & A-1 & A-2 & A-3 \\
\hline \multirow[t]{10}{*}{$\mathrm{A}$} & Ecology & & & & \\
\hline & Length of main road & 10 & 10 & 10 & 1 \\
\hline & Length of secondary road & 1 & 1 & 1 & 10 \\
\hline & Length of carrying path & 1 & 4 & 7 & 10 \\
\hline & Density of main road & 10 & 10 & 10 & 1 \\
\hline & Density of secondary road & 1 & 1 & 1 & 10 \\
\hline & Density of carrying path & 1 & 4 & 7 & 10 \\
\hline & Opened area due to the main road & 10 & 10 & 10 & 1 \\
\hline & Opened area due to the secondary road & 2 & 2 & 1 & 10 \\
\hline & Total of A & 36 & 42 & 47 & 53 \\
\hline \multirow[t]{5}{*}{ B } & Economy & & & & \\
\hline & Corectiion factor $(\mathrm{CF})$ & 1 & 2 & 4 & 10 \\
\hline & Distance of carrying pine resin & 1 & 7 & 8 & 10 \\
\hline & Cost of road construction & 10 & 9 & 5 & 1 \\
\hline & Total of B & 12 & 18 & 17 & 21 \\
\hline \multirow[t]{6}{*}{$\mathrm{C}$} & Social & & & & \\
\hline & Productivity of carrying pine resin & 2 & 3 & 1 & 10 \\
\hline & Productivity of pine resin extraction & 1 & 9 & 5 & 10 \\
\hline & Total of $\mathrm{C}$ & 3 & 12 & 6 & 20 \\
\hline & Total & 51 & 72 & 70 & 94 \\
\hline & Ranking & IV & II & III & I \\
\hline
\end{tabular}


management and types of indicators that become the primary consideration. If all indicators set are taken into consideration in the selection process for forest road network for pine resin extraction, the original nominal values of all indicators cannot be used to determine the best alternative for forest road network for pine resin extraction, as each indicator has its own units which are different from the units of the other indicators. For the purpose of utility analysis, the nominal values of each indicator used need to be transformed into the interval scale values. The results of the transformation from the nominal values to the interval scale values for all indicators are presented at Table 4 . Based on the result of the transformation of the data, it shows that A-3, SQ, A-1, and A-2 have the best 9, 4, 3, and 3 indicators, respectively. The strength of forest road network of A-3 lies in the indicators of the density of secondary roads and paths, $\mathrm{CF}$, mean carrying distance from the tapping area to the pine resin collection area, and productivities of carrying and extracting pine resin. The result of the ranking of alternatives for forest road networks showed that A-3 obtained the highest utility value (rank 1) with the total of utility value of 94 , whereas the total of utility values of A-1, A-2, and SQ reached 72, 70, and 51, respectively. Thus, A-3 is the best alternative for forest road network for pine resin extraction based on the available data. The ranking will change if there are other data that can be used as a basis for decision making. The tendency of decision making will be determined by the extent to which data are available, and this will increase or decrease the advantages of each alternative. Utility analysis is a dynamic and flexible decision making tool, allowing for fast iterations in accordance with the size or amount of available data.

\section{Conclusion}

This study assessed 4 alternatives for forest road network for pine resin extraction using the utility analysis based on the ecological, economic, and social criteria with 13 indicators. The result of the ranking has shown that A-3 was the best road network for pine resin extraction, followed by A-1 at the second rank, A-2 at the third rank, and SQ forest road network at the last rank. The best forest road network for pine resin extraction was a forest road network that has a short main roads, short secondary roads, and short paths used for carrying the pine resin, low road density, low width of opened area, low cost of road construction, small correction factor for carrying the pine resin, and high productivities in the carrying and extracting of pine resin.

\section{References}

Acar H, Barli O, Yoshimura T. 2003. The effects of harvesting, transportation, and stockpiling activities in the resin tapping productivity and quality. In: Proceedings of International Seminar on Harvesting of Non-wood Forest Products. Menemn-Izmir, Turkey, 28 Oktober 2000. http://www.fao.org/docrep/ 005/Y4496E/Y4496E27.htm. [29 Maret 2011].

Abdi E, Majnounian B, Darvishsefat A, Mashayekhi Z, Sessions J. 2009. A GIS-MCE based alternative for forest road planning. Journal of Forest Science 55(4):171-176.

Chamberlain JL, Robert JB, Hammett AL, Araman PA. 2002. Managing for non-timber forest products. Journal of Forestry 100(1):8-14.

Chiou CR, Tsai WL, Leung YF. 2010. A GIS-dynamic segmentation approach to planning travel routes on forest trail network in Central Taiwan. Landscape and Urban Planning 97:221-228. http://dx.doi.org/10. 1016/j.landurbplan.2010.06.004.

CIFOR. 2011. Forests and Non-timber Forest Products. CIFOR Fact Sheets. http://www.cifor.cgiar.org/ publications/corporate/factSheet/NTFP.htm [29 March 2011].

Coffin AW. 2007. From roadkill to road ecology: a review of ecological effects of roads. Journal of Transport Geography 15:396-406. http://dx.doi.org/10.1016/j. jtrangeo.2006.11.006.

Demir M. 2007. Impacts, management and functional planning criterion of forest road network system in Turkey. Transportation Research 41:56-68. http://dx.doi.org/10.1016/j.tra.2006.05.006.

Dietz P, Knigge W, Loeffler W. 1984. Walderschliessung. Hamburg und Berlin: Paul Parey.

Elias 2008. Pembukaan Wilayah Hutan. Bogor: Fakultas Kehutanan. Institut Pertanian Bogor.

Freitas SR, Hawbaker TJ, Metzger JP. 2008. Effect of roads, topography, and land use on forest cover dynamic's in the Brazilian Atlantic Forest. Forest Ecology and Management 259:410-417. http://dx.doi.org/10.1016/j.foreco.2009.10.036.

Food and Agriculture Organization. 2011. Gum Naval Stores: Turpentine and Rosin from Pine Resin. http://www.fao.org/docrep/v6460e05.htm [29 March 2011].

Garcia-Fernandez C, Ruiz-Perez MR, Wunder S. 2008. Is multiple-use forest management widely implementable in the tropic? Forest Ecology and Management 256:1468-1476. http://dx.doi.org/10.1016/j. foreco.2008.04.029.

Guariguata MR, Cronkleton P, Shanley P, Taylor PL. 2008. The compability of timber and non-timber forest products extraction and management. Forest Ecology and Management 256:1477-1481. http://dx. doi.org/10.1016/j.foreco.2008.03.038.

Heinimann HR. 1998. Opening-up planning taking into account environmental and social integrity. In: Proceedings on Environmentally Sound Forest Road and Wood Transport. http://www.fao.org/docrep 
/X0622E/X062E00.htm [29 March 2011].

Irawan WSB, Endang S, Matangaran JR. 2007. Alternatif penduga produksi kopal. Jurnal Manajemen Hutan Tropika 13(3):166-171.

Janowsky VD, Becker G. 2003. Characteristics and needs different user groups in the urban forest of Stuttgart. Journal for Nature Conservation 11:251-259. http://dx.doi.org/10.1078/1617-1381-00056.

Kanzaki K, Ohasi K, Deki T, Miyake T. 1990. On capillary path systems in steep terrain mountain areas. International Journal of Forest Engineering 2:17-21.

Kilchling P, Hansmann R, Seeland K. 2009. Demand for non-timber forest products. Survey of urban consumers and sellers in Switzerland. Forest Policy and Economic 11:294-300. http://dx.doi.org/10.1016/j.forpol. $\underline{2009.05 .003 .}$.

Lacuna-Richman C. 2003. Ethnicity and the utilization of non-wood forest products: Finding from three Philippine villages. Silva Fennica 37(1):129-148.

Liu SL et al. 2008. Evaluating the influence of road network on landscape and regional ecological risk, a case study in Lancang River Valley of Southwest China. Ecological Engineering 34:91-99. http://dx.doi.org/10.1016/j.ecoleng.2008.07.006.

Lotfalian M, Zadeh EH, Hosseini SA. 2011. Calculating the correction factor of skidding distance based on forest road network. Journal of Forest Science 57(11):467471.

Najafi A, Sobhani H, Saeed A, Makhdom M, Mohajer MM. 2008. Planning and assessment of alternative forest road and skidding networks. Croatian Journal of Forest Engineering 29(1):63-73.

Zangemeister C. 1973. Nutzwertanalyse in der Systemtechnik. Eine Methodik zur muldimensionalen Bewertung und Auswahl von Projekalternativen. Muenchen: Wittemansche Buchhandlung. 